\title{
MONUMENTOS DA PEDAGOGIA BRASILEIRA: OS "PARECERES" E "PROJETOS" DE RUI BARBOSA (1).
}

Quem quer que se dedique aos estudos de educação no Brasil e conheça como, entre nós, costumam ser propostos e resolvidos os problemas desta natureza, não pode deixar de reconhecer a importância singular dos famosos "Pareceres" e "Projetos" que Rui apresentou ao Parlamento Imperial de 1882 a 1883.

Não \&́ nossa intenção fazer um estudo minucioso daquelas peças, pois que isto seria tarefa para um longo curso e não apenas para um despretencioso artigo de revista; o que desejamos é tão sòmente chamar a atenção dos leitores para sua riqueza de materia que constitui um verdadeiro tratado de Educação Comparada, em que todos os problemas de ensino estão postos em seu sentido mais elevado, à luz da filosofia, da política e da ciência da educação, segundo os teóricos então mais modernos dos países civilizados do Ocidente.

O valor dêstes trabalhos de Rui parece-nos tão grande que, ressalvadas as diferenças de gênero (e de gênio), podem e devem ser considerados ao lado de "Os Sertões" de Euclides da Cunha.

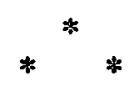

Como se pode fàcilmente verificar pelo esquema anexo, os "Projetos" não se limitam a um ou outro setor do aparelho pedagógico, mas apresentam, como nunca se havia feito antes no país, uma estruturação escolar completa .

Conquanto o "Projeto" tivesse sido apresentado especialmente para servir ao Município Neutro, não deixou de prever a sua generalização, fiscalizada e subvencionada pelo govêrno central, em todo o território brasileiro.

(1). - Obras Completas de Rui Barbosa.

Vol. IX - Tomo I - 1882 - Reforma do ensino secundário e superior.

Vol. $\mathbf{X}$ - Tomo I a IV - Reforma do ensino primário e várias instituiçóes complementares da Instrução Públtca.

Edição do Ministério de Educação e Saúde. 1942-1947 - Rio de Janeiro. 


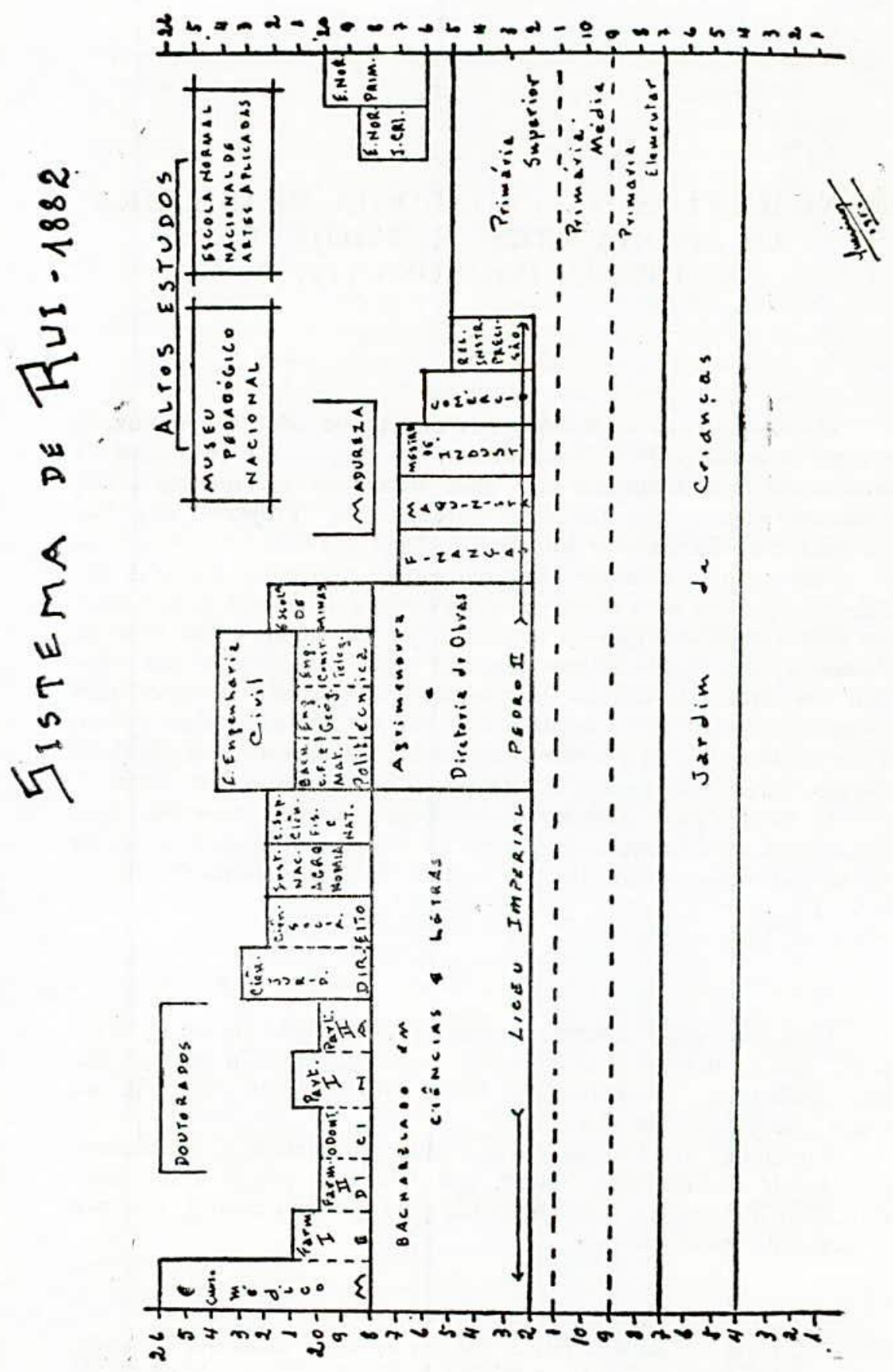


Considerado do ponto de vista da estruturação vertical, os "Projetos" tomam desde a escola pré-primária (que êle mais pitorescamente chamou "Jardim de Crianças"), até os cursos de pós-graduação das formações profissionais superiores, em medicina, direito, etc. Do ponto de vista da estruturaçã̃o horizontal, abrangem os diferentes tipos de escola, especialmente a partir do segundo grau, desde a formação geral comum, até as mais especializadas.

Para cada um dos tipos e graus de escolas, há uma vasta documentação dos fundamentos filosóficos, políticos e metodológicos, documentação buscáda nas mais modernas experiências dos países líderes do desenvolvimento educacional daquele tempo. Sabe-se que, além das obras compulsadas num total de 536 (muitas até do próprio ano de 1882), envolvendo os ensinamentos de cêrca de mil autores citados, desde Platão até Spencer (é interessante notar que faltou Rousseau, apesar de estarem citados Condorcet, Robespierre e Lepelletier), Rui deu-se ao trabalho de investigar pessoalmente as condições do ensino então existente no Rio e ouvir dentre professôres, os que julgava mais abalizados para aconselhá-lo.

Ainda há mais: o sistema de administração central, sob a responsabilidade direta do Ministério do Império ficou planejado com a estruturação de um grupo de órgãos que incluia, além dos serviços especializados, a participação da comunidade, através do que êle chamou "Conselhos Paroquiais"; até um estabelecimento de estudos científicos sistemáticos e permanentes dos problemas mundiais de ensino, êle propôs: o Museu Nacional Pedagógico que era muito semelhante ao que temos hoje sob o nome de "Instituto Nacional de Estudos Pedagógicos".

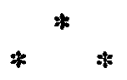

Vejamos, resumindo, como se distribuia e articulava o sistema, pelos seus diversos graus e tipos de escola.

Dos 4 aos 7 anos, as crianças seriam trabalhadas em "Jardins de Crianças". A organização dêste tipo de escola pré-primária era tôda inspirada nas teorias de Froebel, a que Rui deu grande ênfase e valor, propondo que fôsse introduzida no país pela colaboração de espécialistas contratados no estrangeiro e incumbidos de realizar a organização inicial e a preparação dos elementos nacionais. O professorado destas escolas seria preparado (de acôrdo com os planos e direção dos estrangeiros especialistas contratados), nos cursos que o "Projeto" coloca anexos às escolas normais de mulheres. Quanto ao conteúdo educacional dos Jardins de Crianças, recomenda o "Projeto": a) absoluta proibição de todo ensino didático; b) exclusão total da escrita e da leitura; c) ginástica, canto, brincos e trabalhos de Froebel, cultura moral, ensino rigorosamente in- 
tuitivo. Só no terceiro ano e no último semestre, se dariam os elementos constitutivos da linguagem, "que terá comêço pròpriamente, na aula primária".

A parte do "Projeto" referente aos Jardins de Crianças termina com estas recomendáções: "Serão criados, neste município, até vinte Jardins de Crianças, mas sòmente um após o outro, à medida que as necessidades do serviço o fôrem exigindo e QUE A ADMINISTRAÇÃO DISPUZER DE PESSOAL ESMERADAMENTE HABILITADO".

"Para inaugurar entre nós êsse ensino nos Jardins de Crianças, bem como para reger a inspetoria dêsses estabelecimentos NOS DOZE PRIMEIROS ANOS, PELO MENOS, da sua organização, o govêrno contratará pessoal idôneo na Alemanha, Áustria, Suiça, Bélgica, ou nos Estados Unidos, escolhendo-o dentre profissionais de mais nomeada nesta especialidade; PARA O QUE LHES OFERECERA' TOODAS AS VANTAGENS CAPAZES DE ATRAI-LOS”. (Os grifos são nossos).

Pelo exposto e, especialmente, pelo grifado, se constata a importância que Rui atribuia à qualidade do magistério e como reconhecia a colaboração de estrangeiros especializados para os serviços novos de ensino. Este reconhecimento ia até às exigências de não regatear o preço e as vantagens necessárias para atraí-los. Note-se tñmbém que êle não recomendava, mas exigia categòricamente: "o govêrno contratará"; "Serão criados", contraste flagrante com a linguagem de outros projetos contemporâneos, como, por exemplo, o de Franklin Dória, sôbre o Museu Pedagógico (que, por sinal, foi uma "gafe" tremenda dêste parlamentar, "gafe" que levou o próprio Rui a arrazá-lo), em que dizia "Fica autorizado o govêrno a fundar", ou o de Souza Dantas, sôbre um liceu feminino, que usava a mesma expressão "fica autorizado o govêrno a criar"...

Todo o "Projeto" é vazado em linguagem enérgica, como determinações severas a respeito de cada dispositivo, sempre acompanhado, quando era o caso, das penalidades expressas para os transgressores, penalidades que atingiam professôres, autoridades escolares, pais, tutores, etc.

Mas, continuemos a descrição, sem nos determos em comentários, pois cada determinação mereceria considerações especiais, razão por que afirmamos inicialmente serem os "Projetos" dignos de todo um curso e não podermos pretender mais do que uma rápida informação sôbre seu conjunto.

Depois do curso pré-primário, segue-se o primário dividido em três seções (o elementar, o médio e o superior), abrangendo crianças desde os 7 até os 15 anos de idade. Já aqui não podemos deixar de frisar a extensão pretendida para a escola primária que, até hoje, ainda não temos nesta duração de oito anos... 
Nesta escola, continuava dominando a inspiração "froebeliana" e dela seriam "rigorosamente excluídos todos os sistemas mecânicos de ensino, todos os processos que apelem para a memória de palavras, empregando-se constantemente o método intuitivo, o ensino pelas coisas, de que será simples auxiliar o ensino pelos livros". O seu pessoal docente seria preparado pelas escolas normais cuja organização referiremos adiante.

Os cursos primários continham, através de seus oito anos, os seguintes estudos: desenho, escrita, leitura, matemática, ciências físicas e naturais, geografia e história geral e do Brasil, escrituração, direito, economia política e doméstica, trabalhos manuais, canto, ginástica, etc. Cada uma destas disciplinas vem quase programadas para cada uma das secções do curso, além de programadas, esclarecidas metodològicamente.

À primeira vista parece que seria uma pretensão rabelaisiana, mas considerando a duração e dosagem recomendadas para os estudos corrige-se a impressão. O período escolar, apesar de único, era longo, pois, abrangia: a) no curso elementar, 4 horas efetivas de aula com intercalação de recreios de $15^{\prime}$ cada um; b) no curso médio, 4 horas e 30' efetivos de aula, mais 5 recreios de $15^{\prime}$; c) no curso superior, 5 horas e 15' efetivos de aula e 6 recreios de $15^{\prime}$ ' cada um. Comparem-se estas distribuições com as atuais das nossas escolas primárias e mais a extensão do curso, já antes referida e teremos uma idéia do quanto mais se poderia ensinar. . Acresce que, naquele tempo, não havia "gibis", nem rádio, nem futebol, nem cinema, para solicitar a criançada; podia-se portanto propor para as escolas primárias até um programa rabelaisiano...

Para chegar a esta, aparentemente simples, proposição de horários escolares, Rui passa em revista uma imensidade de informações de numerosos tipos de escolas americanas e européias, com as críticas das autoridades educacionais respectivas.

À escola primária tal como Rui a planejou, incumbia dar uma cultura geral bem ampla a todos aquêles que não pudessem ou não quisessem seguir para os cursos médios e superiores. E' que êle já reconhecia a insuficiência das escolas primárias comuns de curta duração, que não chegam a consolidar nem as técnicas elementares da leitura, escrita e cálculo. Por outro lado, na estruturação que projetou, aquêles que pretendiam seguir estudos além, não tinham necessidade de completá-la, podendo passar, já aos doze anos, para as escolas que chamamos hoje impròpriamente de secundárias, mas realmente, pela técnica pedagógica, denominando-se cursos de grau médio. Tais são os atuais ginásios, básicos comerciais, industriais e agrícolas, que, aliás, estão sendo exigidos atualmente pelas populações, como complemẹto indispensável dos primários comuns insuficientes...

Pelas razões antes expostas, os "Projetos" colocam os cursos de grau médio, a partir dos doze anos. Seriam em número de 
7 principais, reunidos todos, na Côrte, no "Liceu Imperial Pedro II", para cuja entrada se exigia um exame baseado no ensino primário médio. a) 0 de "Ciências e Letras" (bacharelado), em 6 anos que, todavia, para os alunos mais capazes, poderia ser feito em 5, reunindo um riquíssimo currículo de línguas e ciências, além do desenho, música, ginástica e exercícios militares. Este bacharelado dava entrada para as escolas superiores de certos tipos, como veremos oportunamente.

b) Os outros 6 cursos tinham caráter eminentemente profissional, correspondiam às nossas escolas técnicas diversas e, como estas atuais, algumas davam entrada a cursos superiores de natureza correspondente. Eram êles: $1^{\circ}$ ) Curso de Finanças, com 5 anos de duração e um currículo específico, além de uma parte geral comum ao de bacharelado em ciências e letras (aliás todos êstes cursos médios profissionais incluiam uma parte semelhante de formação geral), visando a formação "de homens habilitados com a mais sólida educação geral e especial para as repartições do Estado". Era uma escola para os funcionários públicos!...

2.0) Curso de Comércio, com 4 anos de duração, para a carreira que o próprio nome indica.

3. ) Curso de Agrimensura e Diretoria de Obras Agrícolas, também com 5 anos de duração e visando a formação científica dos trabalhadores do campo, já então fazendo imensa falta...

4. ${ }^{\circ}$ Curso de Maquinista, ainda com 5 anos, correspondendo aos nossos atuais técnicos industriais, menos especializados porém, pois que incluiam também as indústrias de construção, visando, em todo caso, a preparação de pessoal tènicamente habilitado para a nascente indústria do país.

$\left.5^{\circ}\right)$ Curso Industrial ou de Maquinista Graduado, ainda de 5 anos, semelhante ao primeiro e com mais os estudos especiais de química, fịção e tecelagem, visando naturalmente, com uma formação mais ampla, os mesmos setores de trabalho anterior.

6. $\left.{ }^{\circ}\right)$ Curso de Relojoaria e Instrumentos de Precisão, com duração de 3 anos apenas, mas visando "abrir álveo a esta espécie de vocação, a cujos produtos nunca faltará procura e copiosa retribuição".

Tal era o riquíssimo plano de ensino do Liceu Imperial cuja organização dos estudos intelectuais e técnicos seria dotada de corpo docente especializado (sempre mandando buscar os necessários no estrangeiro) e oficinas e laboratórios e tudo o mais que Rui previu com a minúcia e fundamentação de que só êle seria capaz. Cêrca de 50 páginas são gastas na discussão do plano do Liceu Imperial, páginas repassadas de sabedoria e que, por si so, valem todo um estudo...

Está previsto também, no plano do ensino de grau médio, o que hoje chamamos madureza, para aquêles que só no fim da adolescência, ou mais tarde ainda, encontram interêsse ou, necessi- 
dade de desenvolver seu cabedal de conhecimentos, ou que fizeram preparatórios por conta própria.

A seguir vêm as escolas de nível superior, incluindo, se não todos, quase todos os tipos de estudo que hoje temos, com os seus respectivos vestibulares, até que o Liceu Imperial estivesse em pleno funcionamento.

A duração dêste cursos superiores acompanha mais ou menos o que hoje ainda prevalece, distribuindo-se da seguinte maneira: 1. ${ }^{\circ}$ Faculdade de Medicina, compreedendo: a) Curso médcio, com oito séries de exames, que poderão ser completados em tempos diversos, desde 4 até 8 anos de estudos, pois, aqui, a unidade é a mıtéria estudada e não o tempo. Este é um princípio que encerra grande sabedoria pedagógica, apesar de tão pouco usado até hoje entre nós; resume-se êle em determinar que se aprenda uma certa quantidade de conhecimentos no tempo que fôr possível a cada um e não (como acontece quando a unidade é o tempo em vez da matéria), que o estudante aprenda o que fôr capaz, dentro de certo tempo pré-determinado. A primeira consequiência desta disposição seria os programas sempre executados integralmente em cada série de estudos e não apenas a parte que o tempo letivo estabelecido viesse a permitir. Foi pena que os "Projetos" de Rui não adotassem esta medida como geral e a impusesse sòmente para alguns dos cursos superiores. Trata-se realmente de um preceito do mais vasto alcance pedagógico, conveniente a todos os graus de ensino.

b) Curso farmacêutico de 1.a classe, com três séries de exames.

c) Curso farmacêutico de 2 .a classe com duas séries.

d) Curso de parteiras de 1.a classe com três séries.

e) Curso de parteiras de 2.a classe com duas séries.

f) Curso de "odontologia dentária" (sic), em duas séries.

Assim, a Faculdade de Medicina compreendia seis cursos diferentes, todos com base na seriação por matéria e não por tempo. Os estudos seriam todos de cunho científico e técnico, dispondo a Faculdade dos laboratórios e clínicas indispensáveis.

2. ${ }^{\circ}$ Faculdade de Direito compreendendo: a) Curso de ciências sociais, com quatro séries de exames.

b) Curso de ciências jurídicas, com cinco séries. Nestes dois cursos da Faculdade de Direito é mui interessante a introdução da Sociologia $e$, não fôra a sistemàticamente longa extensão de suas fındamentações, transcreveríamos aqui a que fêz para esta disciplina, talvez, pela primeira vez lembrada, entre nós, como parte de currículo escolar. Mais interessante ainda é que Rui propôs a Sociologia para substituir o clássico Direito Natural...

3.0) Escola Politécnica compreedendo: a) Curso de Ciências físicas e matemáticas, em três anos, portanto já em base de tempo e não de matéria. 
b) Curso de engenheiro construtor e telegrafista "aos alunos que vencerem as matérias dos dois primeiros anos (do curso anterior) e as do terceiro até a terceira cadeira inclusive...".

c) Curso de engenheiro geógrafo "aos que vencerem o curso geral (de ciências físicas e matemáticas), menos a sexta e sétima cadeiras do terceiro ano, mas fizerem, como os alunos do primeiro curso, um ano de prática no Imperial Observatório". Assim os três cursos da Escola Politécnica, se reduziam a um só curriculum, permitindo a opção dos alunos para se diplomarem em três categorias diferentes, respectivamente: a) bacharel em ciências físicas e matemáticas, b) engenheiro construtor e telegrafista, c) engenheino geógrafo.

O mais interessante da Escola Politécnica é que ela se coloca, intermediàriamente, entre o curso médio de Agrimensura e Diretoria de Obras, do Liceu Imperial e a Escola de Engenharia Civil, que constitui um quarto curso de nível superior, como adiante se indica.

$4^{\circ} .^{\circ}$ Escola de Engenharia Civil, compreendendo um curso de três anos, cujos alunos viriam da Escola Politécnica, com dois meses de prática no Imperial Observatório. Nesta Escola apresenta-se uma particularidade digna de nota: os alunos teriam apenas meio ano letivo de aulas, ocupando a outra metade do ano em trabalhos de campo, nas missões e obras do govêrno, de que apresentariam relatórios para exames de aproveitamento. Para esta parte prática, o próprio govêrno distribuiria os estudantes pelo país a fora... A escola contaria ainda com quatro laboratórios especiais: química aplicada, mineralogia, construções (resistência de materiais) e mais um de geologia e paleontologia.

5..$^{\circ}$ Escola Nacional de Minas, com um curso de três anos, dando entrada também aos estudantes vindos do curso médio de agrimensura.

6..$^{\circ}$ Curso Superior de Ciências Físicas e Naturais, com três séries de exames, funcionando no Museu Nacional, que seria dotado de seis laboratórios: geologia, anatomia comparada, zoologia, antropologia, mineralogia e química aplicada à agricultura.

7. ${ }^{\circ}$ ) Instituto Nacional de Agronomia, com um curso de três anos e seus estudos distribuídos pela Faculdade de Medicina e Museu Nacional, dispondo de uma fazenda modêlo e de estações experimentais em Pernambuco, Bahia, Minas, Rio e São Paulo. Para êste Instituto e suas estações, o govêrno contrataria os especialistas estrạngeiros necessários.

Há nestes cursos superiores uma infinidade de medidas interessantes, das quais queremos destacar especialmente 0 sistema de exames sem notas. Os alunos submetiam-se a bancas que, examinando sôbre tôda a matéria, decidiam por votos: todos os votos favoráveis - aprovação plena; maioria de votos favoráveis - aprovação simples; maioria desfavorável - reprovação. A 
aprovação com distinção seria dada ao aluno que, depois de aprovado uma vez plenamente, fizesse, a requerimento de um dos examinadores, novo exame e obtivesse outra vez todos os votos favoráveis!... Cremos que esta é uma interessante informação para os professôres que quisessem rever seus critérios de notas...

Outra medida que caracteriza o rigorismo com que Rui tratou os problemas do ensino é esta: o professor que, por dois anos, não executou integralmente o seu programa (programa aliás feito pelo govêrno), seria dispensado sumàriamente, sem direito a qualquer remuneração, disponibilidade ou aposentadoria. Só por si, esta medida garantiria um zêlo muito especial no exercício do magistério.

Os cursos superiores admitiam o doutorado com defesa de tese sôbre assunto original, mais ou menos nas mesmas bases em que hoje o temos.

Fora do plano geral dos cursos superiores e dos médios, o sistema de Rui colocava a formação do professorado pré-primário, primário e de algumas disciplinas dos cursos médios, através de três tipos de curso normal: a escola normal para jardins de crianças, a escola normal para professôres primários e a Escola Normal Nacional de Artes Aplicadas, grupo de escolas que constituia um sistema mais ou menos paralelo e complicado cujos detalhes não vamos abordar aqui.

Queremos entretanto destacar uma das particularidades da formação dos professôres primários pela sua originalidade. E' a stguinte:

Os candidatos ao magistério primário, cuja formação era gratuita (a das escolas superiores não o era, antes exigia despesas séras, porque Rui acreditava que o aluno sendo obrigado a elas dedicava-se mais aos estudos), deviam, prèviamente, assinar um contrato com o govêrno, obrigando-se a dedicar-se ao magistério, pelo menos, durante dez anos, depois de formado e, caso faltasse a êste ajuste, então seria cobrado da parte que lhe coube na despêsa que seu curso exigiu dos poderes públicos, despêsa esta que, certamente, importaria numa pequena fortuna.

$$
* * *
$$

A administração do sistema proposto pelos "Projetos", constitui um outro assunto digno de extensas considerações que não faremos pelos limites a que já chegamos. Referiremos apenas o seu aspecto mais original, até hoje não praticado entre nós, apesar de muito usado (e com grandes vantagens), em muitos países estrangeiros. Trata-se do que Rui chamou "Conselhos Escolares de Paróquia". A ampla documentação e argumentação que êle usou para apresentar e defender esta idéia, enchem mais de vinte páginas do III volume da edição do Ministério da Educação. Os 
tıês parágrafos iniciais parecem-nos tão signficativos que não podemos deixar de transcrevê-los na íntegra. Ei-los:

"Associar diretamente o povo à obra do ensino, por meio de instituições eletivas e do imposto especifficamente escolar (refere-se êle aqui à capitação proposta como um dos recursos para o estabelcimento do "Fundo Escolar", outro capítulo importantíssimo), votado por procuradores populares em assembléias locais, tal, a nosso ver, uma das idéias capitais da verdadeira reforma da instrução.

"Não conhecemos outro meio de criar um público interessado nos progressos da educação comum, de despertar as simpatias da massa ativa da nação pela cultura das gerações nascentes, de formar entre a população o hábito, o gôsto, a capacidade para o exercício da função fundamental da sua soberania, e de fiscalizar, apreciar, dirigir, promover $\mathrm{o}$ aperfeiçoamento e a prosperidade do ensino distribuído ao país.

"O povo não pode conhecer a escola, amar a escola, nacionalizar a escola, assimilá-la ao seu caráter, sentí-la entre as suas necessidades, enquanto a escola não tiver os seus comícios cívicos, a sua representação democrática, o seu sistema tributário peł culiar".

Realmente a participação da comunidade na administração escolar, por meio de sistema representativo e eletivo, é um dos problemas que ainda não conseguimos nem propor. A primeira consequiência desta falta é o divórcio entre a comunidade e a escola, cujas relações ficam inteiramente ao sabor da boa vontade e compreensão dos pais e professôres, boa vontade e compreensão estas que nem chegam a definir-se bem, justamente pela falta de um contacto direto, sistematizado e de alta responsabilidade, que só seria estabelecido pelo sistema representativo, obrigatório e legal.

Apesar de discutível, o sistema de funcionamento do ConseIho proposto pelos "Projetos" de Rui, apesar da possibilidade de uma estruturação mais íntima entre a administração escolar e os Conselhos, o princípio é que vale e tem importância, exatamente pelas razões com que êle abre a discussão, conforme transcrevemos acima.

A maneira pela qual Rui estabelece as funções dos Conselhos (mais de competição do que de cooperação e co-responsabilidade), não nos parece a mais indicada pelos fins que se teriam em vista com a sua instituição. Há todavia que aproveitar, no conjunto, a autonomia financeira, a participção de elementos estrangeiros e nacionais sem distinção, a participação dos elementos de ambos os sexos, a representação dos Conselhos Paroquiais no Conselho Superior de Educação, a obrigatoriedade da função pa- 
ra os eleitos, a reelegibilidade indefinida de seus membros, a participação do poder público na sua ação para estimular, corrigir, ou: mesmo castigar, e tantas outras medidas...

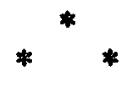

Eis o que nos pareceu suficiente para uma idéia do valor e alcance geral que encerra a famosa obra de Rui.

Discordamos de Thiers Martins Moreira quando escreve, prefaciando a edição do Ministério, que "a tradição fixou e AMPLIOU (o grifo é nosso) a ressonância com que os seus estudos foram ao tempo recebidos e lhes atribuiu virtudes de sabedoria a que talvez nunca ambicionasse seu próprio autor". Estamos mais com Rodolfo Dantas que no parlamento declarou: "Quem quer que se tenha dedicado ao estudo das questōes de ensino há de afirmar com pıazer que êsses trabalhos fariam honra aos mais ilustrados parlamentos da atualidade". Diríamos mais: hoje, passados quase setenta anos, os "Pareceres" e "Projetos" impressionam a quem quer que se dê ao trabalho de lê-los com atenção e interessado nos assuntos que êle trata. Com afirmamos no início dêste artigo, esta obra representa um precioso tratado de Educação Comparada que nerece ser estudado em cursos especializados, tanto quanto, como já o afirmamos antes também, no seu outro gênero, "Os Sertões" de Euclides da Cunha e, com a vantagem de versar um assunto muito mais interessante à atualidade dos problemas nacionais. Há menos de três anos, o Ministro da Educação, lançando o "Projeto de Diretrizes e Bases da Educação Nacional", disse, em discurso, que não se tratava agora de mais uma reforma de ensino, mas de uma revolução. Pois bem; comparando-se os "Projetos" de Rui e o de Mariani, à luz das respectivas situações de fato e contemporâneas de cada um no ensino nacional, o novo, se apresenta como tímido; grande revolução seria o de Rui. A revolução seria tão grande que nem foi tentada... Talvez tenha sido razão, para que os "Projetos" ficassem dormindo indefinidamente nas gavetas do Parlamento Imperial, o fato de êle estar muito acima até das possibilidades de compreensão da maioria dos parlamentos da época. A incompreensão ia até ao desinterêsse, pois, como nos mostra Américo Jacobina Lacombe no prefácio do Tomo I do Vol. X da edição do Ministério, até o companheiro de comissão de Rui, o deputado Ulisses Viana, deixou de ler o trabalho, apesar de dever assiná-lo, como de fato assinou - de cruz!... $O$ bilhete que Ulisses deixou a Rui esclarece bem a mentalidade dos parlamentares de então (poderíamos dizer que a dos de hoje é melhor?...). 
Aliás, não foi o de Rui o único trabalho dêste tipo que mofou nos arquivos; antes já acontecera o mesmo com um de Martim Francisco e o de Mariani parece estar fadado ao mesma destino...

A crítica mais comum que se tem feito a Rousseau, especialmente quanto ao seu monumental "Émile", é que êle propõe uma utopia. Mas Rousseau, talvez prevendo-o, deixou-lhe a resposta já no prefácio da referida obra, onde se encontram estas palavras:

"Proposez ce qui esta faisable, ne cesse-t-on de me répé"ter. C'est comme si l'on me disait: Proposez de faire "ce qu'on fait; ou du moins proposez quelque bien qui "s'allie avec le mal existant. Un tel project, sur certai"nes matières, est beaucoup plus chimérique que les "miens; car, dans cet alliage, le bien se gâte, et le mal "ne se guérit pas. J'aimerais mieux suivre en tout la "pratique établie, que d'en prendre une bonne à demi; "il y aurait moins de contradiction dans l'homme; il ne "peut tendre à la fois à deux buts opposés".

A mesma crítica teria Rui esperado para seus também monumentais "Projetos", pois, na conclusão do "Parecer" sôbre a reforma do ensino primário, escreveu isto que faz lembrar Rousseau:

"Sem uma resolução decidida a vastos sacrifícios e a "transformações radicais, não vos aventureis às dificulda"des da questão.

"Melhor é não encetá-la do que falsear-lhe o caminho.

"Antes o 'statu quo', com tôdas as suas misérias, do que "uma reforma avara, abortiva, sem elevação...".

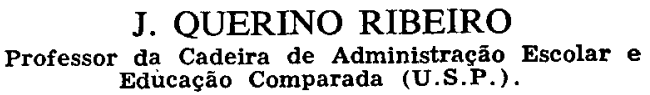

